\title{
Comunicação Interna Estratégica: a aplicação dos quatro campos de intervenção de Duterme na Ometz TV
}

\author{
Náthalli Antoniolli ${ }^{1}$
}

\begin{abstract}
Resumo: O presente trabalho tem o objetivo de explorar os quatro grandes campos de intervenção sugeridos por Duterme em sua teoria sobre ações de comunicação interna como aposta de gestão e intervenção da organização. São eles: gerar e gerir a imagem interna, apoiar as campanhas estratégicas da empresa, servir de suporte à informação geral e avaliar os resultados das ações de comunicação. Para abordar com mais profundidade o foco deste estudo, os campos serão explorados individualmente. Assim, a teoria de Duterme será aplicada sobre a Ometz TV (objeto de estudo deste trabalho), um canal corporativo via satélite que pretende alcançar todas as unidades da holding Ometz Group para informar estrategicamente, treinar profissionais e oferecer novos produtos.
\end{abstract}

Palavras-chave: Comunicação Interna Estratégica; Quatro Campos de Intervenção de Duterme; TV Corporativa; Ometz TV.

\section{Introdução}

Em um mercado cada vez mais competitivo, todo e qualquer diferencial pode ser determinante para que uma organização alcance o sucesso. Pensando nisso, muitas empresas utilizam-se da prática da Comunicação Interna (CI) como estratégia para motivar seus colaboradores e fazê-los sentirem-se peças importantes dentro da organização, o que acaba por imprimir uma imagem interna favorável, capaz de influenciar todo um contexto.

E uma das ferramentas mais utilizadas hoje para este fim, por empresas de grande porte, devido aos desdobramentos das novas tecnologias, é a TV Corporativa, já que se trata de um meio que pode assumir funções que vão além da CI, funções essas essenciais quando se busca atingir um grande número de unidades e colaboradores geograficamente pulverizados, encurtando distâncias, poupando tempo e reduzindo custos, entre outros benefícios.

Pretende-se, por meio deste estudo, explorar os quatro grandes campos de intervenção sugeridos por Duterme (2002, p. 106 - 116) em sua teoria sobre ações de comunicação interna como aposta de gestão e intervenção da organização. São eles: gerar e

\footnotetext{
${ }^{1}$ Jornalista, especialista em Comunicação Empresarial (UTFPR)
} 
gerir a imagem interna, apoiar as campanhas estratégicas da empresa, servir de suporte à informação geral e avaliar os resultados das ações de comunicação.

Para abordar com mais profundidade o foco deste estudo, os campos serão explorados individualmente. Assim, a teoria de Duterme será aplicada sobre a Ometz TV (objeto de estudo deste trabalho), um canal corporativo via satélite que pretende alcançar todas as unidades do Ometz Group - holding formada por 15 empresas nos ramos de ensino de inglês e comunicação - para informar estrategicamente, treinar profissionais e oferecer novos produtos.

Conforme o próprio Duterme (2002, p. 105), as considerações sobre o assunto não pretendem assinalar o funcionamento de um hipotético serviço de comunicação interna normalizada. “A partir de um certo número de procedimentos concretos nas empresas, mas também de considerações teóricas ou de reflexão provenientes da literatura, propomos aqui alguns eixos que nos parecem significativos”. (DUTERME, 2002, p. 105)

Ressalta-se que a coleta de dados sobre o objeto de estudo deste trabalho, a Ometz TV, foi feita por meio de entrevistas com dois dos seus principais mentores: o Diretor Presidente do Grupo, cuja troca de informações foi realizada por e-mail - foram três, no total, para a obtenção do conteúdo necessário ao desenvolvimento do trabalho; e o Diretor Executivo responsável pelo projeto, por meio de dois encontros, pessoalmente.

Porém, antes de se fazer a análise propriamente dita, é preciso passar por teorias que se referem à Comunicação Interna e à TV Corporativa.

\section{A Comunicação Interna e a TV Corporativa}

De acordo com Hingst (2006), tendo que administrar todos os processos em cenários incertos e de grande complexidade para vencer novos desafios, as instituições precisam buscar a melhoria contínua nos diferentes processos organizacionais. Para o autor, as empresas de hoje são dimensionadas, entre outros aspectos, por apresentarem uma estrutura organizacional flexível, com novas formas gerenciais e administrativas.

Com tantas variáveis, as organizações passaram a dar cada vez mais importância ao seu público interno, seus funcionários e terceirizados, 
percebendo-os como parceiros e colaboradores, portanto, formadores de opinião, dos quais dependem a administração e a vitalidade da empresa, num contexto de uma economia globalizada. (HINGST, 2006)

Conforme Kunsch (2003, p. 247), é necessário sensibilizar a alta administração da organização para conseguir seu comprometimento com a comunicação e concebê-la como fator estratégico.

(...) considerar a comunicação como um setor integrado nos processos internos de gestão estratégica, demonstrando seu papel eficaz nas relações interpessoais, interdepartamentais e interorganizacionais, na busca da sinergia organizacional para a consecução dos objetivos globais, criação de valores, cumprimento da missão, melhoria de desempenho (...). (KUNSCH, 2003, p. 247)

Assim, pode-se dizer que a prática da CI tornou-se um diferencial competitivo dentro das organizações. A imagem que os funcionários têm de sua própria empresa é a base de sua imagem externa. E, para edificá-la, a CI e a sua capacidade de produção de mensagens específicas é uma ferramenta importante, já que visa a construir relacionamentos com o público interno. Mas, não são todas as organizações que visualizam a real dimensão e relevância estratégica que as ações de CI podem ter.

A comunicação permeia todas as ações empresariais e dependendo de sua solidez e transparência é responsável por vários êxitos frente às mudanças, pois as decisões serão pautadas em conhecimentos da alta administração e dos empregados. (LUCENA, s/d).

“O serviço de comunicação interna é investido de uma missão estratégica, ou atribui essa missão a si mesmo”. (DUTERME, 2002, p. 116) Esta é a definição proposta da comunicação para o autor: ela está ligada à existência da estratégia global da empresa, está a seu serviço para, por meio de suas ações, apoiá-la. Para Duterme (2002, p. 116), é justamente na sua função estratégica que a comunicação interna pode intervir melhor. 
No ambiente corporativo, a CI é fator essencial na hora de atingir metas e alcançar resultados; quando eficiente e eficaz, tem como principal benefício a construção e o fortalecimento de relacionamentos e favorece o andamento das atividades, reforçando o conceito de que todos são clientes dentro de uma mesma empresa.

Antes de se preocupar em vender produtos ou serviços ao cliente externo, a instituição deve fazer seus colaboradores comprarem suas ideias, valorizarem a imagem da empresa onde trabalham, tornando-os aliados, parceiros, clientes (internos) satisfeitos. E um trabalho de CI, dependendo de como é conduzido, pode ajudar na busca por metas e objetivos comuns que motivem os colaboradores e, desta forma, influenciem na produtividade da empresa. Lisboa e Godoy (2006) defendem a ideia de que uma CI eficaz é um dos fatores fundamentais para a obtenção de êxito nas organizações.

Ou seja, investir em CI é investir na imagem da empresa e na motivação dos seus colaboradores, uma excelente opção para quem pretende expandir os negócios. Mas, é claro, uma das preocupações deve estar relacionada ao seguinte aspecto: para gerar o impacto esperado, é preciso adaptar o conteúdo ao perfil do público que vai receber as informações para se certificar de que ele vai absorver a mensagem; caso contrário, de nada adianta o esforço empenhado no sentido de produzir conteúdo, já que não se chegará ao resultado esperado. Além disso, é importante prever um tipo de comunicação que permita o feedback.

De acordo com Lisboa e Godoy (2006), o processo de CI deve seduzir o colaborador, assegurando esse feedback para a obtenção do sucesso. "Mesmo no processo mais elementar de comunicação, o emissor deve saber qual público quer atingir e quais as respostas desejadas”. (LISBOA e GODOY, 2006)

\footnotetext{
A democratização interna da informação permite que os funcionários saibam mais sobre a empresa, seus processos, produtos/serviços, mercados, metas e desafios, desta forma, eles sentem-se parte do processo e, provavelmente, ficam mais comprometidos e motivados. Estes dois fatores contribuem para a formação da opinião pública interna positiva, além de serem determinantes para o clima organizacional. (LISBOA e GODOY, 2006)
}

Em suma, Lisboa e Godoy (2006) acreditam que a CI é indispensável para que uma empresa se reorganize com base em um forte envolvimento entre colaboradores e 
departamentos/setores e no seu real comprometimento com os resultados e o sucesso da organização.

E, para promovê-la, Hingst (2006) defende a ideia de que é estratégico introduzir nas organizações novas ferramentas tecnológicas, a partir de plataformas digitas, como a rádio corporativa, a intranet, o ensino à distância (e-learning) e a TV Corporativa.

Conforme o autor (HINGST, 2006), o progressivo uso do audiovisual no Brasil se dá a partir dos anos 60, intensificado pela entrada das empresas multinacionais no país, em função da necessidade de divulgar a imagem institucional das organizações e também de promover o treinamento e a capacitação dos profissionais.

De fato, cada vez mais empresas aderem ao uso da TV Corporativa no Brasil como canal de comunicação, para encurtar distâncias, poupar tempo, estreitar relacionamentos, atingir um maior número de pessoas ao mesmo tempo, falar de forma igual com todos, entre outros benefícios, principalmente as que têm grande espalhamento geográfico e um número bastante significativo de colaboradores.

O principal motivo que leva as organizações a optarem pelo uso desse canal é o custo-benefício. O investimento é alto; é necessária toda uma estrutura para potencializar a rápida multiplicação do mais diverso tipo de conteúdo - treinamentos, informações estratégicas, programas motivacionais, atualizações, cursos e afins - para um maior número de pessoas, de todos os departamentos da empresa, mas o retorno que esse canal proporciona é rápido, já que outros custos são reduzidos, como os de deslocamento, por exemplo. Além disso, a TV Corporativa pode aliar a possibilidade de venda de novos produtos, dependendo do caso.

Para isso, a empresa contrata um operador que estabelece o serviço de distribuição. De acordo com Hingst (2006), o custo de implantação de uma estrutura de TV Corporativa completa, atualmente, gira em torno de dois milhões de reais, e envolve a instalação de uma série de equipamentos.

A transmissão pode se dar em tempo real (ao vivo) ou pode ser programada/reprisada .A conexão pode ser feita por meio da internet, através de links próprios, ou via satélite. “(...) as empresas têm se utilizado de duas formas de tecnologia para 
as transmissões: a tecnologia IP-VPN (rede privativa em ambiente Internet Protocol) ou a transmissão via satélite, utilizando antenas parabólicas”. (HINGST, 2006)

Normalmente, opta-se pela qualidade de imagem em high definition vídeo (HDV); neste caso, preza-se muito por um sinal que apresente as melhores características, já que o investimento é alto.

\section{Os quatro campos de intervenção de Duterme}

De acordo com Duterme (2002, p. 106), as ações de CI nas empresas visam a assegurar quatro grandes campos de intervenção: “Gerar e gerir a imagem interna, apoiar as campanhas estratégicas da empresa, servir de suporte à informação geral e, finalmente, quando é possível, avaliar os resultados das ações de comunicação”.

\subsection{Gerar e gerir a imagem interna}

Sobre o primeiro campo - gerar e gerir a imagem interna -, para Duterme (2002, p. 106), pode ser mais tranquilizante dar informações através de um meio de comunicação único, do que confiar na cadeia hierárquica, o que acabaria implicando em considerar todas as possibilidades de transformação e interpretação que a informação pode vir a sofrer.

“Como um espelho das ações desde há muito conduzidas para o exterior, a comunicação interna procura, por diferentes meios, criar e manter, junto dos seus membros, uma imagem 'positiva'”. (DUTERME, 2002, p. 106 e 107) Nesse sentido, o objeto de estudo em questão, a Ometz TV, se propõe a ser esse meio de comunicação específico.

Duterme (2002, p. 107 e 108) afirma também que o jornal da empresa é, muitas vezes, uma espécie de porta-bandeira dos serviços de comunicação interna (SCI), encarregado de fornecer uma informação clara e confiável, de maneira que a gestão interna seja melhorada.

É importante salientar que, além do site institucional, o Ometz Group possui uma página na web alimentada apenas com conteúdo que diz respeito ao público interno da 
empresa. O Portal, hoje o principal canal de CI do Grupo, já conta com uma emissora de televisão corporativa, que veicula um jornal diário, com conteúdos audiovisuais voltados exclusivamente aos colaboradores da empresa.

Com a implantação da Ometz TV, a intenção é manter esse canal na internet e passar a transmitir o jornal diário ao vivo, via satélite - o que não ocorre hoje, em função das limitações da web. A edição completa sempre será disponibilizada no site, posteriormente, todos os dias, como já acontece hoje.

Ou seja, a identidade e o local de origem do jornal, já conhecidos pelo público interno, serão mantidos; a diferença é que a transmissão será feita, também e primeiramente, pela Ometz TV. O intuito é mostrar aos colaboradores que a informação continua sendo transmitida por um meio de comunicação único, apenas replicada, a partir de agora, por dois canais, para aumentar o seu nível de alcance. O controle de qualidade e o caráter oficial das informações divulgadas continuam sendo itens prezados no SCI do Grupo.

Assim, manter as ferramentas com as quais o público interno já está acostumado é fundamental para cultivar a credibilidade que o jornal já construiu, como "porta-bandeira dos serviços de comunicação interna”. Também serão mantidas as ações de comunicação que visam a zelar pela imagem interna positiva da organização.

Vale ressaltar que a viabilidade do novo canal - a TV via satélite - deu-se, principalmente, porque foi possível, para criá-la efetivamente, aliar dois pontos já existentes no Grupo: a prática da comunicação interna, por meio do Portal, e a tecnologia via satélite, já utilizada para transmissões ao vivo das aulas de inglês à distância (e-learning), iniciadas pelo Ometz Group em maio de 2010.

Isso fez com que o custo de implantação fosse muito mais viável; de acordo com a Direção da empresa, o investimento deve girar em torno de um milhão de reais - a metade do valor estimado para se implementar uma estrutura completa.

\subsection{Apoiar as campanhas estratégicas da empresa}

Existe, porém, um ponto que justifica ainda melhor a necessidade de levar o jornal corporativo para dentro da TV via satélite, no caso do Ometz Group. "Embora o apoio a 
campanhas estratégicas se revista de um caráter mais pontual do que a gestão estrita da imagem interna, ele [o SCI] atua, contudo, numa perspectiva de coerência e de lógica 'cultural' interna”. (DUTERME, 2002, p. 111) De acordo com o autor, sobre apoiar as campanhas estratégicas da empresa - o segundo grande campo de intervenção -, estas estão, muitas vezes, ligadas às necessidades de mudança interna.

A transmissão de informações por meio da Ometz TV possibilita que se divulgue mais abertamente as campanhas estratégicas da empresa, o que se evita fazer na TV Corporativa via internet, em função da possibilidade de acesso público que o Portal possui. Ou seja, com sinal codificado, o novo canal visa a driblar as limitações da web, permitindo que se fale mais abertamente sobre as estratégias da empresa já que, neste caso, algumas informações devem ser omitidas da concorrência, em razão da competitividade mercadológica.

“O que se é pedido ao serviço de comunicação interna (SCI) é que se acompanhe o anúncio de decisões tomadas pela Direção, em uma ou várias campanhas de 'informação', que ‘vendam' a qualidade e a lógica dessas decisões”. (DUTERME, 2002, p. 112) Conforme Duterme (2002, p. 112 e 113), em sua dimensão estratégica, a que melhor justifica a sua existência, a CI não escapa à tendência de ser vista como a receita milagrosa que permite vencer todas as dificuldades.

De fato, algumas decisões tomadas pela Direção da empresa tinham, até então, algumas restrições quanto à divulgação por meio do Portal, por razões supracitadas, que dizem respeito à concorrência. Algumas questões importantes acabavam não sendo tratadas, por esse motivo, e eram divulgadas somente por canais considerados mais seguros e privativos, porém menos abrangentes - como chats e e-mails, por exemplo; com a Ometz TV, o SCI terá mais liberdade para falar sobre essas decisões estratégicas. Ou seja, o novo canal estará, de fato, a serviço da estratégica global da empresa para, por meio de suas ações, apoiála, justamente como sugere Duterme ao defender o segundo campo de intervenção.

\subsection{Servir de suporte à informação geral}

Quanto ao terceiro campo - servir de suporte à informação geral -, para além de sua função estratégica, o SCI, conforme Duterme (2002, p. 113), é geralmente encarregado de 
uma forma de centralização da informação e apóia a Direção da instituição na composição e na transmissão de informações.

De uma maneira geral, podemos considerar que a informação relativa às operações segue as lógicas de trabalho e não está dependente do serviço de comunicação interna. No entanto, pode acontecer que informações dessa ordem lhe devam ser confiadas. É o caso, por exemplo, de todas as notícias de ordem prática que devem ser transmitidas a todos num tempo bastante curto. (DUTERME, 2002, p. 113)

Para Duterme (2002, p. 113), o SCI vai procurar aplicar, na função de transmissão de informações, uma lógica unificadora. “Contrariamente aos outros serviços/departamentos, procurará fazer com que as mensagens sejam unificadas no conjunto e que, para além das especificidades a que, evidentemente, é preciso estar atento, a coerência seja mantida”. (DUTERME, 2002, p. 114)

O autor (2002, p. 114) ressalta que, desde que um serviço de comunicação específico se instala na empresa, confiam-lhe - ou ele mesmo se encarrega - a gestão, a centralização, e a homogeneização das ferramentas técnicas de informação.

Neste caso, é exatamente o que a Ometz TV se propõe a fazer: centralizar as informações internas relacionadas a todos os departamentos da empresa, inclusive - e principalmente - as estratégicas, para garantir que sejam transmitidas por um único canal e em um tempo curto, atingindo todos os níveis da organização. Dessa forma, o canal vai auxiliar na gestão da empresa, já que, atualmente, a holding é composta por mais de 10 mil profissionais, geograficamente pulverizados, entre a matriz, em Curitiba, e as cerca de 500 unidades espalhadas por mais de cem cidades brasileiras, além de uma nos Estados Unidos e duas na Argentina.

Ferramenta de suporte à informação geral, cabe ressaltar que a Ometz TV também se propõe a realizar treinamentos à distância que, até o momento, são feitos presencialmente, gerando altos custos - de deslocamento, principalmente. Por meio do novo canal, todas as unidades receberão o mesmo conteúdo, ao mesmo tempo, e a possibilidade de controlar a qualidade da informação gerada, assim como no jornal, é ainda maior, já que parte de um único ponto. Outros treinamentos, que até então não são considerados viáveis, também 
poderão passar a ser realizados. Cursos voltados ao ensino de inglês específico para algumas áreas de interesse - para os alunos da rede - também serão transmitidos por meio do canal.

Eventos pontuais, ao vivo, que cada departamento da empresa promove esporadicamente, até então eram transmitidos apenas pelo Portal - que necessariamente dependia de uma boa conexão de internet nos terminais receptores - e agora passarão a ser transmitidos também via satélite. Um evento voltado à área comercial da empresa marcará o início das atividades da Ometz TV, em maio de 2011.

\subsection{Avaliar os resultados das ações de comunicação}

O quarto campo de intervenção, que consiste em, quando possível, avaliar os resultados das ações de comunicação, é, de acordo com Duterme (2002, p. 114 e 115), algo que as empresas não seguem à risca, embora muitos autores insistam nesse aspecto de vigilância ou avaliação em períodos regulares. "Eis, aliás, uma preocupação que toma amplitude nos últimos anos: como avaliar as ações e o funcionamento da comunicação interna?”. (DUTERME, 2002, p. 115)

Há oito anos produzindo conteúdo e utilizando como meio a internet, avaliar os resultados das ações de comunicação é uma prática que já existe no Ometz Group. O Portal é diariamente monitorado através de um controle no número de visualizações por meio do qual é possível saber, inclusive, quais são os assuntos de maior interesse do público interno.

E foi justamente por avaliar esses resultados que se chegou à conclusão de que investir em CI é, no caso do Grupo, necessário para a gestão da empresa como um todo e, por isso, optou-se por criar a Ometz TV.

Pretende-se acompanhar os resultados do novo canal de diversas formas, assim que suas transmissões forem iniciadas. Além do contato direto com os franqueados responsáveis pelos pontos receptores -, todos terão a possibilidade de registrar um feedback por meio dos canais internos disponibilizados pela empresa. Haverá, ainda, a possibilidade de monitorar esses pontos receptores de sinal. 


\section{A união dos quatro campos}

Com o objetivo de sistematizar a análise, reuniu-se, na tabela abaixo, os quatro campos de intervenção de Duterme com suas respectivas características principais e a forma como cada um se aplica no objeto de estudo em questão.

\begin{tabular}{|c|c|c|}
\hline $\begin{array}{l}\text { CAMPOS DE } \\
\text { INTERVENÇÃO }\end{array}$ & CARACTERÍSTICAS & $\begin{array}{l}\text { COMO SE APLICA } \\
\text { NA OMETZ TV }\end{array}$ \\
\hline $\begin{array}{l}\text { 1. Gerar e gerir a } \\
\text { imagem interna }\end{array}$ & $\begin{array}{l}\text { - Dar informações através de um } \\
\text { meio de comunicação único; } \\
\text { - Criar e manter, junto dos seus } \\
\text { membros, uma imagem positiva; } \\
\text { - Fornecer informação clara e } \\
\text { confiável, de maneira que a gestão } \\
\text { interna seja melhorada, por meio do } \\
\text { jornal da empresa, o porta-bandeira } \\
\text { do SCI. }\end{array}$ & $\begin{array}{l}\text { - A Ometz TV se propõe a manter a unidade em } \\
\text { relação aos meios de comunicação já existentes } \\
\text { no Grupo; } \\
\text { - Serão mantidas as ações de comunicação que } \\
\text { visam a zelar pela imagem interna positiva; } \\
\text { - A identidade do jornal, que o público interno já } \\
\text { conhece, também será mantida, assim como o } \\
\text { controle de qualidade das informações. }\end{array}$ \\
\hline $\begin{array}{l}\text { 2. Apoiar as } \\
\text { campanhas } \\
\text { estratégicas da } \\
\text { empresa }\end{array}$ & $\begin{array}{l}\text { - Atuar numa perspectiva de } \\
\text { coerência e de lógica cultural interna, } \\
\text { com ações baseadas na necessidade } \\
\text { de mudança interna. }\end{array}$ & $\begin{array}{l}\text { - A Ometz TV vai permitir que informações } \\
\text { estratégicas sejam mais abertamente tratadas, já } \\
\text { que possui sinal codificado e, portanto, a } \\
\text { concorrência pode deixar de ser uma } \\
\text { preocupação; } \\
\text { - Também vai possibilitar que as decisões } \\
\text { tomadas pela Direção sejam mais amplamente } \\
\text { divulgadas. }\end{array}$ \\
\hline $\begin{array}{l}\text { CAMPOS DE } \\
\text { INTERVENÇÃO }\end{array}$ & CARACTERÍSTICAS & $\begin{array}{l}\text { COMO SE APLICA } \\
\text { NA OMETZ TV }\end{array}$ \\
\hline $\begin{array}{l}\text { 3. Servir de suporte } \\
\text { à informação geral }\end{array}$ & $\begin{array}{c}\text { - Encarregar-se de uma forma de } \\
\text { centralização das informações e apoio } \\
\text { à Direção, por meio de uma lógica } \\
\text { unificadora. }\end{array}$ & $\begin{array}{l}\text { - A Ometz TV se propõe a centralizar as } \\
\text { informações, principalmente as de cunho } \\
\text { estratégico, para atingir todos os colaboradores, } \\
\text { buscando, assim, garantir a qualidade do } \\
\text { conteúdo; } \\
\text { - O canal também se propõe a transmitir } \\
\text { treinamentos voltados a todo o corpo funcional, } \\
\text { além de cursos específicos que serão } \\
\text { comercializados nas franquias; } \\
\text { - Todo evento ao vivo, promovido por qualquer } \\
\text { departamento da empresa, será transmitido pela } \\
\text { Ometz TV. }\end{array}$ \\
\hline $\begin{array}{l}\text { 4. Avaliar os } \\
\text { resultados das } \\
\text { ações de } \\
\text { comunicação }\end{array}$ & $\begin{array}{l}\text { - Verificar os resultados, o efeito das } \\
\text { ações de comunicação em períodos } \\
\text { regulares. }\end{array}$ & $\begin{array}{l}\text { - Prática já existente no Ometz Group, alguns dos } \\
\text { critérios aplicados na avaliação de outros canais } \\
\text { serão igualmente utilizados para verificar os } \\
\text { resultados da Ometz TV; } \\
\text { - Pretende-se acompanhar os resultados por meio } \\
\text { do contato direto com os franqueado, pelo } \\
\text { feedback registrado nos canais internos }\end{array}$ \\
\hline
\end{tabular}




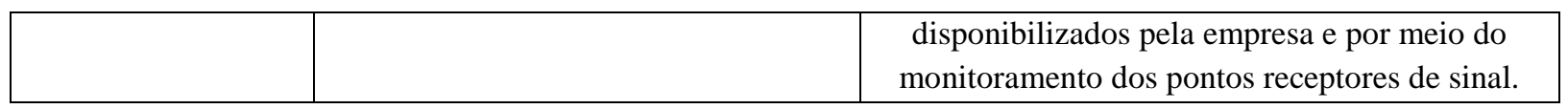

Com base na tabela, que sintetiza a análise, parte-se, então, para as considerações finais do estudo.

\section{Considerações finais}

A partir de um panorama sobre a TV Corporativa como meio utilizado na Comunicação Interna, analisando-se individualmente os quatro campos de intervenção sugeridos pela teoria de Duterme, e aplicando-os sobre o objeto de estudo deste trabalho, foi possível - como mostra de forma sintética a tabela acima - aproximar todos eles, por meio da identificação de pontos característicos da Ometz TV, que condizem com o que propõe os grandes campos de intervenção do autor.

O fato de ser um canal com sinal codificado, via satélite, privativo, deixou ainda mais clara a importância da escolha da TV Corporativa, especificamente, como meio para a nova fase que a empresa pretende inaugurar no que diz respeito ao seu serviço de comunicação interna.

Conclui-se, portanto, que, se o projeto da Ometz TV já era considerado viável por diversas razões, sua viabilidade e importância para a comunicação interna do Ometz Group ficou ainda mais evidente, a partir do momento em que os quatro campos de intervenção de Duterme foram identificados na proposta do projeto, mesmo antes do seu lançamento; ou seja: por meio desta análise, foi possível reiterar os benefícios que o novo canal, via satélite, proporcionará ao serviço de CI da empresa, a partir da perspectiva do autor. 


\section{Referências Bibliográficas}

ALVAREZ, Mônica. Públicos Internos: o número $1 . \quad$ s/d http://www.comtexto.com.br/2convicomcciMonicaAlvarez.htm Disponível em 04 de fevereiro de 2011.

DUTERME, Claude. A comunicação interna na empresa: a abordagem de Palo Alto e a análise das organizações. Lisboa: Instituto Piaget, 2002. Trad. Ludovina Figueiredo.

HALLIDAY, Tereza. A Construção da Imagem Empresarial - Quem fala, quem ouve? Palestra proferida em 19/11/1999.

HINGST, Bruno. TV Corporativa: uma nova perspectiva para a comunicação organizacional. XXIX Congresso Brasileiro de Ciências da Comunicação. 2006. http://www.rpbahia.com.br/biblioteca/intercom2006/resumos/R0952-1.pdf Disponível em 01 de fevereiro de 2011.

KUNSCH, Margarida Maria Krohling. Planejamento de relações públicas na comunicação integrada. 4.ed. São Paulo: Summus Editorial, 2003.

LISBOA, Flavi Ferreira Filho e GODOY, Leoni Pentiado. A Contribuição da Comunicação Organizacional na Obtenção do Comprometimento dos Colaboradores. XXIX Congresso 
Brasileiro de Ciências da Comunicação. UnB. 2006. http://www.rpbahia.com.br/biblioteca/intercom2006/resumos/R1318-2.pdf Disponível em 01 de fevereiro de 2011.

LUCENA, Valdecira Bezerra. A tecnologia como parceira da Comunicação Empresarial Interna. s/d http://www.comtexto.com.br/2convicomcciValdeciraLucena.htm Disponível em 04 de fevereiro de 2011.

PEREIRA, Monalisa Leal. Comunicação Interna: aliada ou vilã - você decide! s/d http://www.comtexto.com.br/2convicomcciMonalisaPereira.htm Disponível em 04 de fevereiro de 2011. 